\title{
Da natureza heurística da Teoria do Texto
}

\section{Maria Antónia Diniz Caetano Coutinho ${ }^{1}$}

Resumo: Este trabalho pretende retomar e desenvolver aquilo a que Marcuschi (2004/2009, p. 94-95) chamou a "natureza heurística da teoria textual", enquadrando-a do ponto de vista teórico e metodológico, a partir de diferentes autores e perspectivas que, de alguma forma, contribuem para consolidar a noção. A esta discussão conceitual segue-se a análise de um texto, que exemplifica a abordagem anteriormente proposta. O percurso desenvolvido permite evidenciar as diferentes acepções em que pode ser entendida a área disciplinar da Linguística do Texto e, em última análise, enfatizar a distinção possível entre Linguística do texto e Teoria do Texto.

Palavras-chave: Abordagem heurística. Complexidade. Linguística do Texto. Teoria do Texto.

\begin{abstract}
This paper aims at developing what Marcuschi (2004/2009, p. 94-95) called the "heuristic nature of textual theory". By discussing different authors and approaches anyhow related with that notion, a theoretical and methodological framework will be provided. This conceptual discussion is followed by the analysis of a text, which exemplifies the approach previously proposed. Through these steps, different understandings of Text Linguistics domain can be highlighted, as well as the distinction that should be drawn between Text Linguistcs and Text Theory.

Keywords: Heuristic approach. Complexity. Text Linguistics. Text Theory.
\end{abstract}

Résumé: Avec la présente contribution, nous nous proposons de reprendre et de développer ce que Marcuschi (2004/2009, p. 94-95) a appelé la "nature heuristique de la théorie textuelle". D’après différentes approches théoriques et méthodologiques, nous essaierons de mieux cerner la question dont il est question. A cette discussion conceptuelle nous rajouterons une analyse de texte, à titre d'exemple de l'approche proposée. Ce parcours nous conduira à mettre en évidence les différentes conceptions du domaine de la Linguistique du Texte et, en dernière

\footnotetext{
${ }^{1}$ Docente da Faculdade de Ciências Sociais e Humanas da UNL (Departamento de Linguística), é investigadora do Centro de Linguística da Universidade Nova de Lisboa, Portugal, coordenando o projeto Pretexto, Práxis, Conhecimento e Texto. É membro do grupo de pesquisa ALTER Análise de Linguagem, Trabalho Educacional e suas Relações (CNPq) e membro associado do grupo Langage-Action-Formation (Universidade de Genève).
}

Este artigo está licenciado sob forma de uma licença Creative Commons Atribuição 4.0 Internacional,

que permite uso irrestrito, distribuição e reprodução em qualquer meio, desde que a publicação

original seja corretamente citada. https://creativecommons.org/licenses/by/4.0/deed.pt BR. 
analyse, à souligner une distinction possible entre Linguistique du Texte et Théorie du Texte.

Mots-clès: Approche heuristique. Complexité. Linguistique du texte. Théorie du texte.

\section{Introdução}

Como anuncia o título, este trabalho pretende retomar e desenvolver aquilo a que Marcuschi (2004/2009, p. 94-95) chamou a "natureza heurística da teoria textual". Ainda que outros autores se tenham referido, de forma mais ou menos implícita ou indireta, a esta questão, é a Marcuschi que devemos uma formulação inequívoca: “A teoria textual é muito mais uma heurística do que um conjunto de regras específicas enunciadas de modo explícito e claro" (MARCUSCHI, 2004/2009, p. 94-95).

É este ponto de vista que procuraremos desenvolver nas páginas que se seguem: começaremos por apresentar as razões que permitem fundamentar a concepção heurística da teoria do texto; na seção seguinte, perspectivaremos um método de trabalho adequado; analisaremos depois um texto, a título de exemplo; finalmente, sistematizaremos as conclusões possíveis.

\section{Enquadramento}

O principal fator que, a nosso ver, sustenta o caráter heurístico da teoria do texto tem a ver com a complexidade do objeto - e, consequentemente, com o modelo que se adota para descrever o funcionamento desse mesmo objeto. 
A noção de texto como objeto complexo pode ser associada ao paradigma da complexidade, tal como formulado por Edgar Morin (1982) e já desenvolvido em trabalhos anteriores (MORIN, 2001, 2003[1999], 2014). Segundo Morin (1982), este paradigma opõe-se ao da simplificação, que funciona por redução e por disjunção: redução da complexidade do real a descrever e a analisar, disjunção do real em parcelas sem relação entre si, a conduzir, no limite, à (hiper)especialização. Não pode deixar de ser curioso constatar que o paradigma da simplificação, que constituiu um pressuposto fundamental da ciência moderna, foi posto em causa no âmbito das ciências ditas naturais. Com efeito, a descoberta de estruturas macroscópicas de não equilíbrio, para as quais deixa de funcionar o segundo princípio da termodinâmica (segundo o qual a evolução de um sistema tendia necessariamente para um estado estacionário), pôs radicalmente em causa as concepções clássicas de determinismo e reversibilidade, colocando em primeiro plano "fenômenos de instabilidade, de bifurcação, de temporalização" (PRIGOGINE, 1990, p. 216) - que, na história de um sistema, o fazem evoluir num processo de auto-organização. Não havendo aqui condições para desenvolver, de forma exaustiva, as questões que acabam de ser enunciadas, limitarnos-emos a sublinhar as consequências que daí podemos tirar para o campo específico em que nos situamos: enquanto objetos naturais (por oposição a objetos forjados laboratorialmente ou por abstração teórica), os textos partilham a complexidade dos sistemas abertos (ou caóticos), cuja evolução não é (completa ou necessariamente) previsível, uma vez que envolvem elementos (ou subsistemas) diversos, bem como uma 
multiplicidade de interações entre esses mesmos elementos ${ }^{2}$. Assim, apesar da condição linguística que os caracterizam, por serem produzidos numa (pelo menos numa) língua natural, os textos são irredutíveis a essa mesma condição (estritamente) linguística.

Apesar da oportunidade das conclusões a que se pode chegar, pela via que acabamos de expor, ainda que de forma resumida, parecenos hoje absolutamente essencial sublinhar o contributo decisivo de Voloshinov ([1930]1981) que, por uma via diferente, aponta no início do século XX aquilo a que hoje podemos chamar a complexidade dos textos. Figura determinante na elaboração de uma epistemologia interacionista social ${ }^{3}$, Voloshinov defende uma concepção inequivocamente social da linguagem, de que decorre o caráter inevitavelmente dialógico da mesma. Se estes fatores determinam a conhecida orientação metodológica descendente que o autor preconiza para o estudo da língua, não será menos significativo o fato de o caráter dialógico da linguagem perspectivar também a (re)identificação, ou o recorte, do próprio objeto de estudo:

Par conséquent, toutes les relations qui sortent des limites de l'énonciation-monologue constituent un tout. Il va de soi que ce tout lui-même, ainsi que ses formes, restent également en dehors du champ de la réflexion linguistique. Et, de fait, celleci ne s'aventure guère au-delà des éléments constitutifs de l'énonciation-monologue. Sa portée maximale est celle de la phrase complexe (la période). La construction de l'énonciation complète, la linguistique en laisse la responsabilité à d'autres disciplines: la rhétorique et la

${ }^{2}$ Cf. Miranda \& Autor, 2005.

3 Também no que diz respeito à recusa da (hiper)especialização foram precursores os autores do início do século passado que assumiram o quadro do interacionismo social: um dos aspectos do programa deste quadro epistemológico passa pelo estabelecimento de uma ciência do humano como uma ciência (re)unificada, capaz de se constituir como alternativa ao espartilhamento disciplinar herdado do positivismo. 
poétique. Ele-même est incapable d'aborder les formes de composition du tout (VOLOSHINOV, [1930]1981, p. 113).

Sem falar propriamente de complexidade, Voloshinov ([1930]1981, p.157) refere, no entanto, "l'«élémentarité» fondamentale de toutes les catégories linguistiques". E conclui:

De cette façon, si nous restons dans les limites des catégories grammaticales effectives de la linguistique contemporaine, nous ne mettrons jamais la main sur l'énonciation complète insaisissable. Les catégories de la langue nous tirent obstinément de l'énonciation et de sa structure vers le système abstrait de la langue (VOLOSHINOV, [1930]1981, p.157).

Se regressarmos à linguística nossa contemporânea, podemos dizer que a complexidade dos textos tem sido muitas vezes apontada, nomeadamente por Jean-Michel Adam, que sempre teve o cuidado de situar os aspetos tipológicos do texto num contexto mais amplo. Vejase como o autor formulava esta questão há já trinta anos:

(...) dès que l'on cherche à carctériser le récit, la description ou l'argumentation, apparaissent immédiatement une hétérogénéité et une complexité qui semblent constitutives des discours en langue naturelle. (...). La réflexion que je mène actuellement sur la description (...) me pousse à considérer qu'une aproche typologique reste utile sous certaines conditions et qu'elle n'a de sens que si, parallèlement à cette tentative de systématisation on pose que chaque système de base (narratif, explicatif, descriptif, etc.) n'est qu'un moment d'une complexité à théoriser (ADAM, 1987, p. 51-52). 
Em 2011, na introdução à edição revista do clássico Les textes: types et prototypes (Adam, 1992), o autor sublinha sem hesitação a mudança e a evolução do seu próprio posicionamento, relativamente à compreensão do componente composicional numa lógica de complexidade:

Le présent ouvrage a été entièrement revu afin d'éliminer les ambiguïtés qui persistaient dans le texte de 1992 et sa première révision en 1997. La précision la plus importante portera sur le fait qu'on ne passe pas de façon compositionnelle des séquences au texte. Le rang textuel de composition est bien plus complexe et polystructuré que l'idée de continuité linéaire d'articulation des séquences entre elles jusqu'au rang textuel global ne le laissait entendre. Je pensais que la modularité du modèle impliquait clairement la complexité des facteurs et des composants; il est évident que ce n'était pas le cas (ADAM, [1992] 2011a, p. 12).

Em última análise, só em trabalhos posteriores (ADAM, 2012; 2015) virá a compreender-se mais claramente o ponto de vista do autor: em primeiro lugar, na medida em que a reflexão sobre a complexidade textual é agora explicitamente associada ao paradigma da complexidade, tal como formulado por Edgar Morin (1982) e como já atrás referido; em segundo lugar, na medida em que esse posicionamento afasta de forma inequívoca uma abordagem modular (em sentido estrito). Com efeito, vemos o autor preconizar uma epistemologia e um modelo de trabalho não reducionistas: "le modèle [...] s'efforce de ne pas isoler, séparer, mais de distinguer des modules ou axes d'analyse, dans une théorie qui cherche à les penser toujours ensemble" (ADAM, 2015, p.14). Como se compreende a partir da passagem citada, e como decorre necessariamente da epistemologia da 
complexidade, a referência a um funcionamento modular não pode aqui ser tomada em sentido estrito4: não se trata de módulos entendidos como subsistemas funcionalmente distintos e autônomos, mas sim de eixos de análise, perspectivados numa dinâmica de conjunto.

Convém lembrar que já também de Beaugrande \& Dressler (1981) privilegiaram um modelo interacional de funcionamento da linguagem, em que cada componente considerado interage com o(s) outro(s) e todos se controlam reciprocamente - em detrimento de modelos modulares, em que cada componente funciona de forma independente (BEAUGRANDE; DRESSLER, 1981, p. 32). Por isso - e ao contrário do que pode fazer crer uma primeira leitura rápida - os autores não fazem depender a textualidade da simples ocorrência de cada um dos sete parâmetros considerados; sublinhando que a possibilidade de um nãotexto exigiria uma total ausência de parâmetros da textualidade, que tornasse impraticável a comunicação, afirmam: "Such a borderline can depend on factors outside the text itself, e.g., tolerance and prior knowledge of the participants present, or type text in use" (BEAUGRANDE; DRESSLER, 1981, p. 34). Por isso - e ao contrário do que aparentemente se reteve como o essencial de Beaugrande \& Dressler (1981) - os sete parâmetros da textualidade (que os autores entendem funcionar como princípios constitutivos) não aparecem como verdadeiramente decisivos; eles dependem de princípios reguladores, que não definem a forma de comportamento comunicativo/textual, mas controlam as condições de comunicação

\footnotetext{
${ }^{4}$ Sobre a questão da modularidade, veja-se Nolke \& Adam (1999).
} 
textual: "Those factors [efficiency, effectiveness and appopriateness] control what people say at least as much as do the abstract rules of grammar and logic" (BEAUGRANDE; DRESSLER, 1981, p. 34).

Não é este o ponto de vista assumido na Gramática do Português (RAPOSO et al., 2013), que subordina as questões textuais ao tratamento sintático e semântico, no quadro da frase composta e da frase complexa: a parte 3 , bloco D $\left({ }_{3} \mathrm{D}\right)$, que se intitula Sintaxe e Semântica - Frase Composta e Frase Complexa, desdobra-se em cinco capítulos (34 a 39), sendo o capítulo 34 intitulado "Organização Textual e articulação de orações”. A organização deste capítulo é apresentada nos seguintes termos:

[...] em 34.1, apresentamos os parâmetros da textualidade, isto é, os princípios linguísticos e pragmáticos que subjazem ao texto; em 34.2, focamos especificamente o parâmetro da coesão textual, nomeadamente a coesão referencial, temporal e estrutural; em 34.3, discutimos a forma como estão estruturados os tópicos de um texto (estrutura temática) e também a forma como se organiza a informação nova e informação conhecida (estrutura informacional). Finalmente, apresentamos em 34A.1 uma revisão dos critérios que permitem estabelecer tipologias textuais e, em 34A.2, algumas propriedades que caracterizam o discurso oral (MENDES, 2013, p. 1694).

Assim, os responsáveis pela Gramática do Português e pelo capítulo em causa5 criam um equívoco: assumem à partida (na organização e no título) uma concepção de texto como prolongamento da frase, mas fazem simultaneamente intervir questões textuais de

${ }^{5}$ O capítulo 34 (Organização textual e articulação de orações, p. 1691-1746) é assinado por Amália Mendes; 34A (Tipologias textuais, p. 1747-1755), explicitamente referido como "apêndice" (n. 45, p. 1747) é assinado por Maria Fernanda Bacelar do Nascimento. 
ordem comunicativa ${ }^{6}$, sem um cabal esclarecimento da articulação entre essas diferentes perspectivas.

Poder-se-ia apontar o retrocesso desta opção relativamente ao capítulo "Aspetos linguísticos da organização textual” que Inês Duarte (1983) assina, na Gamática da Língua Portuguesa (MATEUS et al., 1983): neste caso, a autora começa por referir os parâmetros da textualidade apontados por Beaugrande (1980), concentrando-se depois, majoritariamente, na apresentação dos mecanismos de coesão. Apesar de estarem aqui ausentes noções que são hoje centrais, no âmbito de uma linguística do texto e do discurso, o capítulo é coerente relativamente ao propósito de tratar do que é tematizado no título, a saber, "aspetos linguísticos da organização textual".

A legitimidade de diferentes abordagens é indiscutível - e outra coisa não caberia aqui, quando defendemos a complexidade do objeto, irredutível a um único ângulo de entrada. Por isso, mais do que simplesmente sublinhar o retrocesso atrás referido, parece-nos importante assinalar que o que falta à Gramática do Português é um posicionamento claro e inequívoco sobre a forma como entende (ou não entende) o objeto texto. Neste sentido, e de acordo com uma distinção relativamente consensual na bibliografia especializada, um claro posicionamento em termos de gramática transfrástica (ou gramática de texto) seria coerente com a ausência do objeto texto na organização geral da obra (a par da ausência de discurso e, mesmo, da

\footnotetext{
${ }^{6}$ De forma não exaustiva, sublinhe-se que são tidos em conta os sete parâmetros da textualidade, segundo Beaugrande \& Dressler, 1981, e que se refere explicitamente que "os princípios estruturais de coesão não se aplicam da mesma forma a todos os géneros textuais" (MENDES, 2013, p. 1693).
} 
componente pragmática) ${ }^{7}$.

Fecharemos então esta seção com a distinção estabelecida por Coseriu (2007) entre gramática transfrástica (ou gramática transoracional ou gramática de texto) e linguística do texto: o objeto da primeira são os textos como nível de estruturação das línguas; o da segunda são os textos como nível de linguagem autônomo, independente das línguas em que se realizam. Sublinhe-se, em primeiro lugar, a relatividade desta independência: trata-se, sobretudo, de distinguir duas formas diferentes de entender o objeto texto; e é o próprio autor que também explicita o papel da gramática transfrástica como "une science auxiliaire indispensable pour la linguistique du texte" (COSERIU, 2007, p. 322) ${ }^{8}$. Note-se também a forma como o autor explica o que se deve entender por esse nível de linguagem autônomo que são os textos:

Ya sólo el hecho de que exista una clase de contenido que es propiamente contenido de textos, o contenido dado a través de los textos, justifica la autonomía del nivel textual. Por eso, la lingüística del texto, o, más exactamente, lo que se ha denominado aquí "verdadera" y propia" lingüística del texto, es una lingüística del sentido (COSERIU, 2007, p. 156, grifo nosso).

Compreender-se-á certamente que só os textos como nível de linguagem autônomo (que são objetos comunicativos, empíricos e

\footnotetext{
${ }^{7} \mathrm{~A}$ introdução começa por destacar o fato de "serem considerados todos os níveis de análise linguística" - fonético e fonológico, morfológico, lexical, sintático e semântico ( $p$. XXV); mais à frente, na apresentação da organização interna da gramática, refere-se que o Bloco $D$ "é dedicado à organização textual e às frases constituídas por mais do que uma oração, nomeadamente em estruturas de coordenação e estruturas de subordinação" e que no Bloco H estão em causa "aspectos linguísticos que se situam na fronteira entre a sintaxe, a semântica e a pragmática". (p. XXIX).

8 Um bom exemplo desta relação corresponde ao capítulo sobre aspectos linguísticos da organização textual (Duarte, 2003), já atrás brevemente comentado.
} 
complexos) suscitem ou apelem a uma abordagem heurística. Dela nos ocuparemos, mais em pormenor, na seção seguinte.

\section{Uma metodologia heurística}

A dimensão heurística da teoria do texto só é sustentável quando aplicada a objetos comunicativos, empíricos e complexos, que se constituem num plano específico, distinto do das línguas em que são produzidos. É essa condição que ficou assumida na seção anterior. É também essa, parece-nos, a orientação proposta por Marcuschi:

(...) dizer que os critérios definidores das propriedades de um texto são heurísticos equivale a propor que sejam indicativos e sugestivos para permitir a produção e a compreensão, mas não regras rígidas e formais como condições necessárias e suficientes para a boa-formação textual (MARCUSCHI, 2004/2009, p. 95).

Como se poderá calcular, o ponto de vista assumido por Marcuschi cria espaço e abertura para textos que poderemos dizer imprevisíveis. Reside aqui, provavelmente, o nó da questão: textos imprevisíveis tendem a ser tidos como marginais e pouco úteis para o trabalho em linguística, na medida em que não permitem o reconhecimento de regularidades. Pode, no entanto, pôr-se em dúvida que o reconhecimento de regularidades seja verdadeiramente uma finalidade exclusiva, ou simplesmente maior, do trabalho científico. Sublinhe-se, a este propósito, a distinção evocada por Rastier entre a via nomotética, segundo a qual a ciência pretende/procura a formulação de leis, e a via idiográfica, para a qual "conhecer é caracterizar a 
especificidade e a singularidade dos objetos singulares" (RASTIER, 2011, p. 28).

A este propósito, e uma vez mais, é particularmente significativo o desafio colocado pela física (e pela epistemologia científica): quando se lida com sistemas abertos (também ditos caóticos), a tendência para a tipificação pode ser substituída com vantagem pela consideração de singularidades. Veja-se a forma como Prigogine e Stenghers (1993, p.109) expõem isso mesmo:

\begin{abstract}
Descrever um sistema, fazer dele o modelo, já não é reduzi-lo a um tipo geral após ter eliminado as singularidades; é antes tentar calcular em que condições estas singularidades poderão produzir efeitos. Trata-se, pois, de determinar com precisão quais as singularidades que nos interessam, e o que nos arriscaremos a desprezar, sabendo que a validade desta escolha nunca será mais do que uma questão de circunstância.
\end{abstract}

Uma leitura possível desta relação entre tipificação versus singularidade(s) passa, no que diz respeito a textos e à linguística do sentido que deles se ocupa, pelos limites de generalização possível face à singularidade própria de cada texto:

No existe ninguna técnica para la interpretación de los textos que posea validez universal [...]. No es posible prever qué relaciones de los signos pueden comprobarse en un texto determinado, si se considera éste en su individualidad; lo único realmente posible es la elaboración de un catálogo de posibilidades generales disponibles para la creación de sentido (COSERIU, 2007, p. 246-247) 


\section{A não-coesão como singularidade}

Reconhecida como uma propriedade dos textos - pelo menos desde as obras fundadoras de Halliday \& Hasan (1976), Beaugrande (1980) e Beaugrande \& Dressler (1981) - entende-se que a coesão dá conta da interdependência das formas em ocorrência na superfície do texto: "The surface components depend upon each other according to grammatical forms and conventions, such that cohesion rests upon gramatical dependencies" (BEAUGRANDE; DRESSLER, 1981, p. 3).

Um texto como o que se reproduz na Figura 1 não evidencia, no entanto, relações de coesão gramaticalmente estabelecidas - a não ser as que se podem considerar de ordem intrafrástica.

Figura 1: Copo da UCAL

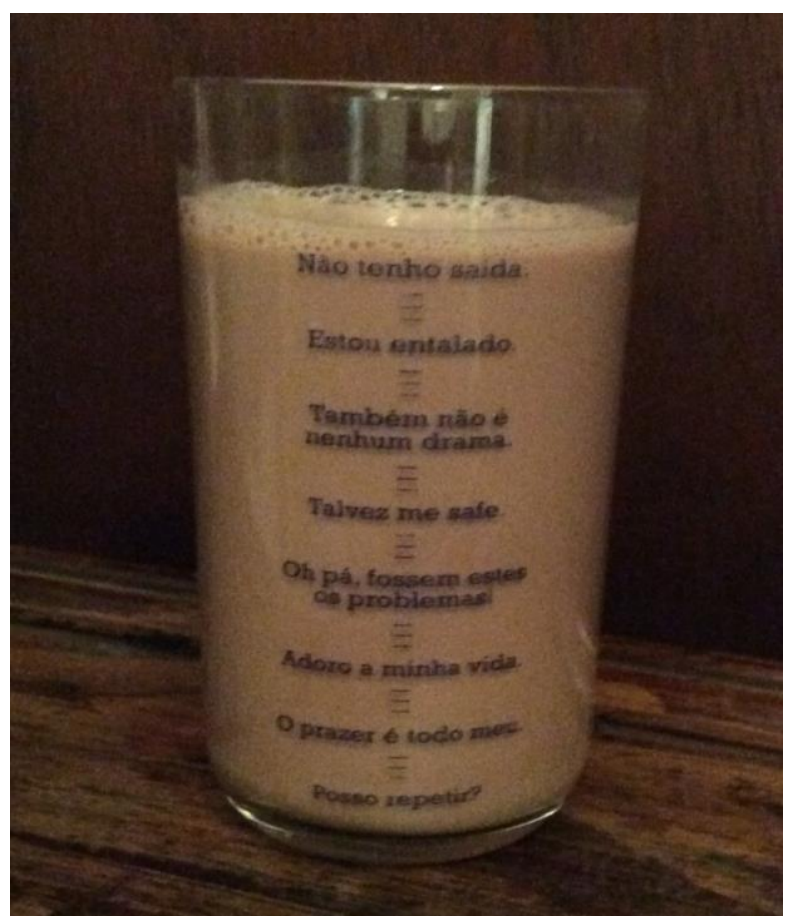

Fonte: Fotografia de Arquivo Pessoal 
Em última análise, poder-se-ia mesmo perguntar se se trata efetivamente de um texto, ou apenas de uma sucessão de frases desligadas entre si. No entanto, o pressuposto que assumimos aqui descredibiliza a hipótese de um não-texto, pelo menos de forma radical: na medida em que uma produção linguística acontece em contexto comunicativo, estaremos perante um texto (ainda que mais ou menos conseguido). Deste ponto de vista, a pergunta que interessa colocar é outra: por que razão, ou com que finalidade, convém a um texto como o da Figura 1 a ausência de coesão? Por outras palavras: que efeito decorre da singularidade não coesiva do texto em análise?

A Figura 2, que mostra o outro lado do mesmo copo exibido na Figura 1, permite evidenciar que estamos perante um gênero da atividade publicitária: de um lado, o logotipo do produto publicitado, neste caso a marca (de leite) UCAL; do outro, o corpo do texto. 
Figura 2: Copo da UCAL (logotipo)

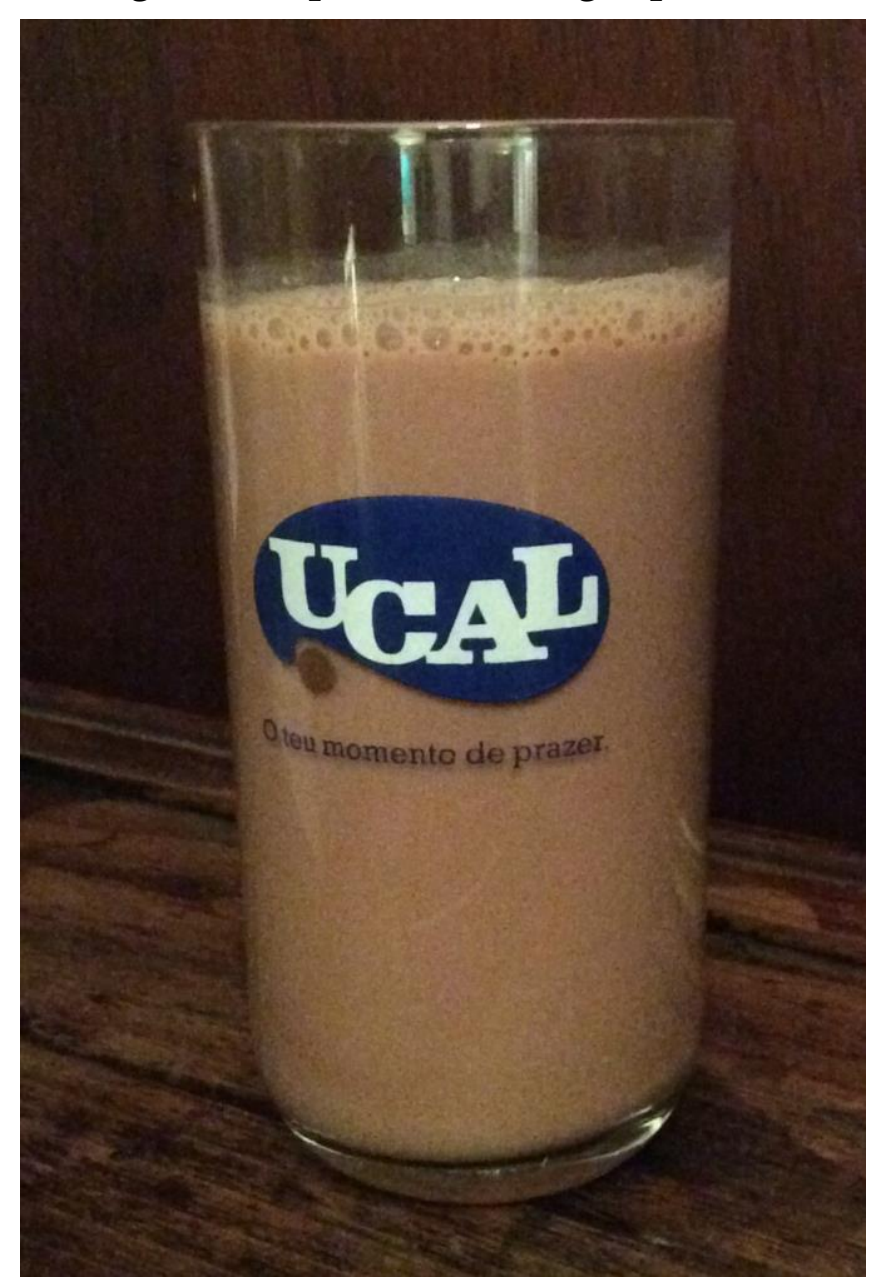

Fonte: Fotografia de Arquivo Pessoal

Se logo e corpo do texto constituem as seções maiores do plano de texto, este último compreende ainda uma sucessão de enunciados desligados entre si, do ponto de vista de mecanismos de coesão (gramatical). No entanto, do ponto de vista discursivo, todos esses enunciados têm em comum o fato de se constituírem como expor implicado: na maior parte dos casos ocorrem dêiticos de primeira pessoa (formas pronominais ou sujeitos nulos, possessivos, formas verbais flexionadas); em dois dos enunciados não há ocorrências desse 
tipo, mas verifica-se o registo dialogal próprio do discurso interativo, ou expor implicado (“Também não é nenhum drama”; “Oh pá! Fossem estes os problemas!"). Além disso, do ponto de vista temático é evidente uma progressão que vai do disfórico para o eufórico, respectivamente, a partir do primeiro enunciado, no cimo do copo, para o último enunciado, no final do copo. Escolhas lexicais, expressões idiomáticas, frase exclamativa e registo oral(izante) ou mesmo popular configuram essa evolução temática. Acrescente-se ainda o fato de os enunciados estarem separados por um elemento semiográfico recorrente (três pequenos traços horizontais). Se associarmos estes elementos ao fato de se inscreverem num suporte específico - um copo - tudo se encaixa de forma inesperadamente natural: (1) o tipo discursivo implicado simula a voz de quem bebe; (2) o caráter temático disfórico inscrito no cimo do copo evoca a atitude de quem bebe (álcool) para "afogar mágoas"; (3) a progressão euforizante reproduz o efeito do álcool ingerido; (4) o separador semiográfico discretiza os estados, primeiro francamente disfóricos ("Não tenho saída" e "Estou entalado"), depois progressivamente capazes de relativização ou indiferença ("Também não é nenhum drama", "Talvez me safe", "Oh pá, fossem estes os problemas!"), finalmente eufóricos (“Adoro a minha vida”, “O prazer é todo meu"); (5) o último enunciado ("Posso repetir?") corresponde ao movimento de não interrupção do beber, como forma de prolongar um prazer induzido (ou um estado alterado). Na prática, atesta um parâmetro do gênero anúncio publicitário, na medida em que assegura a representação do prazer induzido pelo produto e, como tal, serve a 
finalidade social do gênero (induzir a compra ou, neste caso, o consumo).

Nada pode provar em absoluto que todo este processo, aplicado ao beber (leite com chocolate) UCAL, seja decalcado do beber álcool. Mas tudo leva a crer que assim seja: tanto a produção como a compreensão deste texto lidam com um conjunto de elementos que não se podem reduzir a regras nem sequer a princípios gerais; esses elementos só funcionam (só produzem sentido) de forma interrelacionada, no equilíbrio (relativo, instável) do texto em causa.

Qual é então, em última análise, o contributo que daqui podemos extrair para a teoria do texto?

\section{Sistematização}

Nos limites do presente trabalho, limitar-nos-emos a sublinhar duas orientações maiores, que se podem considerar habitualmente estranhas à área disciplinar da linguística e que só uma teoria heurística permite enquadrar. A primeira reitera a necessária articulação entre linguístico e não linguístico, como condição de produção e de interpretação de sentido(s) textualmente elaborado(s):

En la medida en que el sentido se expresa en los textos no sólo lingüísticamente, sino también extralingüísticamente $-\mathrm{y}$ ello en una medida considerable-, la "verdadera" y "propia" lingüística del texto debe ir más allá de lo lingüístico (COSERIU, 2007, p.304). 
A segunda, complementar, reitera o papel central da análise (micro)linguística: “(...) la lengua constituye el punto de partida inexcusable de todo trabajo interpretativo" (COSERIU, 2007 p. 298).

Pode então considerar-se alheia a uma abordagem heurística a chamada - impropriamente chamada, se aceitarmos o ponto de vista de Coseriu (2007) - linguística do texto, fundamentalmente preocupada com o nível transfrástico e que, como tal, conviria antes entender como gramática transfrástica (ou gramática de texto). A abordagem heurística só é possível no âmbito da "verdadeira" Linguística do Texto, se quisermos continuar a usar os termos da distinção de Coseriu (2007): uma linguística preocupada com o sentido, que aceita privilegiar, quando necessário, os caminhos imprevisíveis da sua construção (em detrimento da obrigatoriedade de generalização).

Resta saber em que medida esta (verdadeira) Linguística do Texto coincide ou não com uma (eventual) Teoria do Texto. Certamente que sim - sempre que se tomar esta última expressão como simples (para)sinônimo da primeira. Mas há outras possibilidades. A Teoria do Texto pode incluir uma linguística do sentido, mas não se esgotar nela; pode configurar-se como um espaço viável para desenvolver uma abordagem dos textos que não se confine a um tratamento linguístico nem o dispense; uma abordagem que pense as dimensões social e psicológica, praxiológica e gnosiológica, através de uma compreensão aprofundada dos diferentes planos da linguagem; uma abordagem que repense (a concepção de) língua, através dos próprios textos e, ainda através deles, redescubra o papel decisivo da linguagem, no vivido das 
pessoas e nas experiências coletivas e sociais ${ }^{9}$. Uma Teoria do Texto de cariz (radicalmente) interacionista social. A desenvolver.

\section{Referências}

ADAM, J.-M. Introduction aux problèmes du texte. In. ADAM, J.-M. (Dir.). Faire texte. Fronteires textuelles et opérations de textualisation. Besançon: Presses Universitaires de Franche-Comté, 2015, p. 11-33.

. Discursivité, généricité et textualité. Distinguer pour penser la complexité des faits de discours. Recherches, v. 56, p. 9-27, 2012.

Les Textes: types et prototypes. Paris: Armand Colin, [1992] 20112.

. Textualité et séquentialité. L'exemple de la description. Langue Française,

n. 74, p. 51-72, 1987.

BEAUGRANDE, R. Text, Discourse and Process. Toward a multidisciplinary science of texts. London: Longman, 1980.

BEAUGRANDE, R. de; DRESSLER, W. Introduction to Text Linguistics. London; New York: Longman, 1981.

COSERIU, E. Lingüística del texto. Introducción a la hermenéutica del sentido. Madrid: Arco/Libros, 2007.

AUTOR, M. A. Language in Action: Epistemological and Methodological Issues. In: CORREIA, C. N. et al. (Eds.). From Language to Discourse. Newcastle upon Tyne: Cambridge Scholars Publishing, 2014. p.224 - 235.

. Teoria do Texto. Relatório de unidade curricular no âmbito do concurso para Professor Associado na área disciplinar de Linguística (Linguística do Texto e do Discurso) da Faculdade de Ciências Sociais e Humanas da Universidade NOVA de Lisboa. (Edital no 164/2012). Lisboa: NOVA FCSH, 2012. Não publicado.

Texto(s) e competência textual. Lisboa: Fundação Calouste Gulbenkian; FCT, 2003. Disponível em: <http://hdl.handle.net/10362/15753>.

${ }^{9}$ Cf. Autor, 2012. 
. Saberes e dizeres. Revista da Faculdade de Ciências Sociais e Humanas,

DUARTE, I. Aspetos linguísticos da organização textual. In: MATEUS et al. Gramática da língua portuguesa. Lisboa: Caminho, 2003, p. 85-123

HALLIDAY, M. A. K.; HASAN, R. Cohesion in English. London; New York: Longman, 1976.

MARCUSCHI, L. A. Linguística do texto: o que é e como se faz? Recife: Editora Universitária da UFPE, 2004/2009.

Produção textual, análise de gêneros e compreensão. São Paulo: Parábola Editorial, 2008.

MENDES, A.; NASCIMENTO, M. F. B. de . Sintaxe e semântica - frase composta e frase complexa. In: RAPOSO, E. P. et al. Gramática do Português. Lisboa: FCG, 2013. p. 1691-1755.

MIRANDA, F.; AUTOR, M. A. Gêneros de texto e formas de interação. In: Atas do Colóquio Internacional Linguagem e Interação. (Unisinos, S. Leopoldo/Brasil). Publicação em CD-Rom, 2005.

MORIN, E. Science avec conscience. Paris: Ed. Fayard, 1982.

NØLKE, H.; ADAM, J.-M. (Dirs.). Approches modulaires: de la langue au discours. Lausanne : Delachaux et Niestlé, 1999.

PRIGOGINE, I.; STENGHERS, I. Simples/Complexo. In: ENCICLOPÉDIA Einaudi. Lisboa: Imprensa Nacional, Casa da Moeda, 1993. p. 98-111.

RASTIER , F. La mesure et le grain. Sémantique de corpus. Paris: Champion, 2011.

VOLOSHINOV, V. N. La structure de l'énoncé. In: TODOROV, T. Le principe dialogique. Paris: Seuil, [1930]1981. p. 287-316.

Recebido em 12/12/2017.

Aprovado em 22/12/2017. 